\title{
A human model of inflammatory cardio-metabolic dysfunction; a double blind placebo-controlled crossover trial
}

Nehal N. Mehta ${ }^{1,2,4^{*}}$, Sean P. Heffron ${ }^{1}$, Parth N. Patel ${ }^{1}$, Jane Ferguson ${ }^{1}$, Rachana D. Shah ${ }^{1}$, Christine C. Hinkle ${ }^{1}$, Parasuram Krishnamoorthy ${ }^{1}$, Rhia Shah ${ }^{1}$, Jennifer Tabita-Martinez ${ }^{1}$, Karen Terembula', Stephen R. Master ${ }^{3}$, Michael R. Rickels ${ }^{2}$ and Muredach P Reilly ${ }^{1,2^{*}}$

\begin{abstract}
Background: Chronic inflammation may contribute to insulin resistance (IR), metabolic syndrome and atherosclerosis although evidence of causality is lacking in humans. We hypothesized that very low-dose experimental endotoxemia would induce adipose tissue inflammation and systemic IR during a low-grade but asymptomatic inflammatory response and thus provide an experimental model for future tests of pharmacologic and genomic modulation of cardio-metabolic traits in humans.

Methods: Ten healthy, human volunteers (50\% male, 90\% Caucasian, mean age $22.7 \pm 3.8$ ) were randomized in a double-masked, placebo-controlled, crossover study to separate 36 -hour inpatient visits (placebo versus intravenous-LPS $0.6 \mathrm{ng} / \mathrm{kg}$ ). We measured clinical symptoms via the McGill pain questionnaire and serial vital signs. Plasma and serum were collected for measurement of cytokines, C-reactive protein, insulin and glucose, serial whole blood \& subcutaneous adipose tissue mRNA expression were measured by real-time PCR. HOMA-IR, a wellvalidated measure of IR was calculated to estimate insulin resistance, and frequently sampled intravenous glucose tolerance testing (FSIGTT) was performed to confirm an insulin resistant state. We performed ANOVA and within subject ANOVA to understand the differences in cytokines, adipose tissue inflammation and IR before and after LPS or placebo.

Results: There was no significant difference between placebo and LPS in clinical responses of symptom scores, body temperature or heart rate. However, low-dose endotoxemia induced a rapid and transient 25 -fold induction of plasma TNF-alpha and 100-fold increase in plasma IL-6 (Figure 1B) ( $p<0.001$ for both) both peaking at two hours, followed by modest inflammation in adipose tissue with increases in mRNA levels of several inflammatory genes known to modulate adipose and systemic insulin resistance. Adipose tissue mRNA levels of IL-6 (peak 6-fold, ANOVA $F=27.5, p<0.001$ ) and TNF-alpha (peak 1.8-fold, $F=2.9, p=0.01$ ) increased with MCP-1 (peak 10-fold, $F=5.6$, $p<0.01$ ) and fractalkine $(C X 3 C L 1)$ (peak 15-fold, $F=13.3, p<0.001$ ). Finally, HOMA-IR was $32 \%$ higher following LPS compared to placebo $(p<0.01)$ and insulin sensitivity declined by $21 \%$ following LPS compared to placebo $(p<0.05)$
\end{abstract}

\footnotetext{
* Correspondence: nehal.mehta@uphs.upenn.edu; muredach@mail.med. upenn.edu

${ }^{1}$ Cardiovascular Institute, Perelman School of Medicine at the University of Pennsylvania, Philadelphia, PA, USA

${ }^{2}$ Institute for Diabetes, Endocrine and Metabolism, Perelman School of Medicine at the University of Pennsylvania, Philadelphia, PA, USA

Full list of author information is available at the end of the article
} 
Conclusions: We present a low dose human endotoxemia model of inflammation which induces adipose tissue inflammation and systemic insulin resistance in the absence of overt clinical response. Such a model has the potential for broad and safe application in the study of novel therapeutics and genomic influences in cardio-metabolic disease.

Keywords: Inflammation, Obesity, Atherosclerosis, Insulin resistance

\section{Background}

Chronic inflammation is a central feature in the pathophysiology of insulin resistance (IR) and diabetes [1-3], both of which are risk factors for the development of atherosclerosis [4]. Indeed, IR and overt type-2 diabetes may emerge during human infections and sepsis [5] via activation of toll-like receptor 4 (TLR-4) signaling. TLR4 also may be activated by endogenous ligands that are increased in diet induced obesity and IR [6]. Further, experimental studies in mouse models of TLR4 deficiency demonstrate a reduction in diet induced obesity [6] and atherosclerosis [7].

The TLR4 pathway can be activated in humans by exogenous administration of standardized preparations of lipopolysaccharide (LPS) under Food and Drug Administration oversight. We and others have shown that insulin resistance [8,9], adipose tissue inflammation [10] and atherogenic lipoprotein changes [11,12] observed acutely during this experimental stimulation resemble those observed chronically in obesity, insulin resistance and atherosclerosis. However, our prior experimental work, which used a moderate dose of LPS (3 $\mathrm{ng} / \mathrm{kg}$ ) [8], was associated with clinical symptoms and modulation of counter-regulatory hormones which limit the potential broad application for the study of cardiometabolic diseases.

There is a great need for development of a feasible human model of low grade inflammation in which novel therapies and endogenous exposures, such as genotypic variation, can be tested for their modulation of inflammatory atherogenic stress. In this paper, we address the hypothesis that low dose endotoxemia (LPS $0.6 \mathrm{ng} / \mathrm{kg}$ ) induces biologically relevant inflammatory metabolic changes in the absence of overt clinical responses. Our goal was to investigate the feasibility of this potential subclinical model in humans in order provide a tool for testing drugs, diets and genes that modulate inflammatory cardio-metabolic disease.

\section{Methods}

\section{Endotoxemia clinical protocol}

We performed a double blind, placebo-controlled, random sequence, crossover trial of young, healthy, nonsmoking males and females $(\mathrm{n}=10)$ who had no vascular disease, diabetes, kidney or liver dysfunction, active infection, elevated glucose, dyslipidemia, hypertension, nor treatment with anti-hypertensive or lipid-modifying medications. After informed consent, participants met with a Clinical Translational Research Center (CTRC) dietician for a weight maintenance diet (controlled for saturated fat and cholesterol intake) to start two-weeks before each of the two 36- hour stays. They were admitted to the CTRC at $6 \mathrm{pm}$ of Day 0, given a standard meal at $7 \mathrm{pm}$ and administered a McGill Short Form Pain Questionnaire [13] and an intravenous (IV) catheter was placed for the administration of saline $(100 \mathrm{~mL} /$ h) at $10 \mathrm{pm}$. At 5:30 am on Day 1, another IV catheter was placed for the purpose of serial blood sampling, and baseline blood was drawn prior to slow administration, over three minutes, of lipopolysaccharide (LPS) $(0.6 \mathrm{ng} /$ $\mathrm{kg}$, US standard reference endotoxin; lot\# CC-RE-LOT$1+2$ from Clinical Center, National Institutes of Health) or placebo (saline). Following injection, a standardized breakfast was provided.

Serial blood samples and the McGill Short Form Pain Questionnaire were taken at one, two, four, six, 12, 18 and 24 hours following the LPS or placebo intervention. Blood pressure was measured every 15 minutes for the first eight hours following LPS/placebo administration and hourly for the remaining 16 hours of the stay. Heart rate was measured hourly for the first eight hours postintervention and then at 12, 16 and 24 hours. Subcutaneous adipose tissue biopsies under local anesthesia (1\% lidocaine) were obtained 5 minutes prior to LPS/placebo injection and at four, 12 and 24 hours following injection. The four serial subcutaneous gluteal adipose biopsies were performed from a different site each time - i.e. left upper, left lower, right upper, and right lower regions. Subjects were also provided standardized meals at $12 \mathrm{pm}$ and $6 \mathrm{pm}$ on Day 1 . Twenty-four hours following the administration of LPS or placebo (approximately 6:00 am on Day 2), a frequently sampled intravenous glucose tolerance test (FSIGTT) was performed to calculate insulin sensitivity [14]. The crossover CTRC visit occurred one month following the first visit in which identical procedures and protocol were followed.

\section{Blood measures}

Serial blood draws occurred in tubes containing EDTA, placed on ice briefly and centrifuged for the isolation of 
plasma, which was divided into aliquots and stored at $-80^{\circ} \mathrm{C}$ until the time of analyses. Plasma levels of insulin, growth hormone and cortisol (radio-immunoassays (RIA), Linco Research, St Charles, MO), and as previously described $[8,10,15]$, plasma levels of tumor necrosis factor alpha (TNF), interleukin-6 (IL-6) (Linco Multiplex ELISAs on Luminex IS100; Austin TX) were measured in duplicate per manufacturers' guidelines. Plasma lipids and glucose were measured enzymatically (Wako Diagnostics, Richmond, VA) on a Hitachi 912 automated chemistry system in a Center for Disease Control-certified lipid laboratory as described previously $[15,16]$, and biomarker C-reactive protein (CRP; high sensitivity) levels were assayed using immunoturbidemetry as described [17].

\section{Adipose tissue biopsy and RNA expression}

Adipose tissue samples obtained via needle aspiration biopsy as described [8,10,15] were treated with RNA Later ${ }^{\circledR}$ (Qiagen, Valencia, CA), snap frozen and stored at $-80^{\circ} \mathrm{C}$. Fat tissue RNA was extracted with the RNeasy total RNA kit (Qiagen, Valencia, CA), providing approximately 1-4 g RNA per $100 \mathrm{mg}$ tissue, and subjected to RT-PCR followed by quantitative PCR (qPCR) on an Applied Biosystems 7300 Real-Time PCR System (ABI, Foster City, CA). Adipose tissue mRNA levels of IL-6, TNF, suppressor of cytokine signaling (SOCS)-1, SOCS-2, SOCS-3, SOCS-6, monocyte chemoattractant protein (MCP)-1 and fractalkine (CXC3L1) were determined as we have described $[8,10,15]$. Variability in total cDNA concentrations between samples was normalized by subtracting the beta-actin $C_{t}$ value from the target $C_{t}$ value for each sample. The comparative $C_{t}$ method was used to analyze changes in gene expression [18]. The $\Delta C_{t}$ for each post-LPS sample was compared to the mean $\Delta C_{t}$ for all pre-LPS samples in a single individual using the relative quantitation $2^{-(\Delta \Delta C t)}$ method to determine foldchange from baseline.

\section{Insulin sensitivity \\ Estimation of insulin sensitivity and pancreatic beta-cell function}

Twenty four hours prior to LPS and 24 hours following LPS, the insulin sensitivity index (SI) was derived from the frequently sampled intravenous glucose tolerance test (FSIGTT). We chose the FSIGTT as the method for determining insulin sensitivity since the test also provides a measure of pancreatic beta-cell function via the acute insulin response to glucose (AIRg), allowing simultaneous assessment for an effect of endotoxemia on the beta-cell. The FSIGTT was conducted using the insulinmodified approach as previously described [19]. SI was derived from Bergman's minimal model [14,20] using MINMOD Millennium software [21]. Of the 10 subjects
(20 potential FSIGTT exams), we had complete data at both visits in five subjects; two subjects had inconsistent glucose administrations at one of the visits, two subjects had inconsistent timing of insulin administration at one of the visits and one subject had extreme outlier data (>2.5 standard deviations for insulin and glucose). Complementary estimates of insulin resistance and beta-cell function, the homeostasis model assessment for insulin resistance, HOMA-IR index [glucose $(\mathrm{mmol} / \mathrm{L}) \mathrm{x}$ insulin $(\mu \mathrm{U} / \mathrm{mL}) / 22.5]$, and the HOMA for beta-cell function, HOMA-B index [insulin $(\mu \mathrm{U} / \mathrm{mL}) \times 20 /$ glucose $(\mathrm{mmol} /$ L) - 3.5], were calculated independently of FSIGTT data using fasting glucose and insulin values at 24 hours after placebo and 24 hours after LPS.

\section{Statistical analyses}

Data are presented as mean and standard deviation for continuous variables and frequencies for categorical variables. Baseline characteristics between males and females were tested using t- tests for normal data and KruskalWallis testing for non-parametric data. The effect of LPS on clinical parameters, plasma biomarkers, metabolic measures and adipose tissue mRNA levels were tested by repeated measures analysis of variance (ANOVA). When significant global differences were found in ANOVA, post hoc paired t-tests were used to compare time-points. Data are presented in the figures as mean and standard error of the mean. Analyses were performed using STATA 12.0 (College Station, TX). Statistical significance was defined as a $p$-value $<0.05$. We did not correct for multiple testing; plasma cytokine data represent our primary endpoints with additional traits analyzed to provide complementary information regarding the model impact on diverse cardio-metabolic and biological pathways.

\section{Results}

Baseline characteristics of participants

Participants were healthy volunteers (50\% male, 90\% Caucasian, age $22.7 \pm 3.8$ ) with normal blood pressure, plasma lipoproteins and BMI as well as expected gender differences in HDL-C, TG and CRP levels (Table 1). The baseline glucose, SI and HOMA-IR measurements were consistent with an insulin sensitive, glucose-tolerant healthy sample.

\section{Systemic inflammatory response to low-dose endotoxemia}

Low-dose endotoxemia induced a rapid and transient induction of plasma TNF-alpha (Figure 1A) and IL-6 (Figure $1 \mathrm{~B}) \quad(p<0.001$ for both) both peaking at two hours. There was a later increase in white blood cells (Figure 1C) (peak four hours, $p=0.007$ ), and subsequent increase of the biomarker, CRP (Figure 1D) (highest level 
Table 1 Baseline characteristics of Study Participants $(\mathrm{N}=10)$

\begin{tabular}{|c|c|c|}
\hline & & Mean (SD) \\
\hline \multirow[t]{3}{*}{ Age (years) } & & $22.7(3.8)$ \\
\hline & Males & $20.4(3.2)$ \\
\hline & Females & $25.0(2.9)$ \\
\hline BMI $\left(\mathrm{kg} / \mathrm{m}^{2}\right)$ & & $24.0(2.3)$ \\
\hline Waist Circumference (m) & & $0.85(0.06)$ \\
\hline TNF-a (pg/mL) & & $0.9(0.4)$ \\
\hline IL-6 (pg/mL) & & $1.5(0.8)$ \\
\hline \multirow[t]{3}{*}{ CRP (mg/L) } & & $1.2(1.4)$ \\
\hline & Males & $0.5(0.2)$ \\
\hline & Females & $1.8(1.7)$ \\
\hline Systolic Blood Pressure (mmHg) & & $115.5(7.2)$ \\
\hline Diastolic Blood Pressure $(\mathrm{mmHg})$ & & $69.1(3.3)$ \\
\hline Heart rate (bpm) & & $58.9(9.9)$ \\
\hline Temperature (K) & & $309.3(255.4)$ \\
\hline Total Cholesterol (mmol/L) & & $4.42(0.83)$ \\
\hline \multirow[t]{3}{*}{ HDL-C (mmol/L) } & & $1.54(0.33)$ \\
\hline & Males & $1.25(0.09)$ \\
\hline & Females & $1.83(0.19)$ \\
\hline \multirow[t]{3}{*}{ Triglycerides (mmol/L) } & & $0.89(0.34)$ \\
\hline & Males & $0.76(0.25)$ \\
\hline & Females & $1.03(0.39)$ \\
\hline LDL-C (mmol/L) & & $2.22(0.56)$ \\
\hline $\begin{array}{l}\text { *FSIGTT-insulin sensitivity index } \\
\left(\mathrm{SI}, \times 10^{-4}\left(\mu \mathrm{U} / \mathrm{ml}^{-1} \cdot \mathrm{min}^{-1}\right)\right.\end{array}$ & & $3.4(1.1) \wedge$ \\
\hline †HOMA-IR insulin resistance index & & $10.4(2.77)$ \\
\hline$\left(\mathrm{AIRg}, \mu \mathrm{U} \cdot \mathrm{ml}^{-1} \cdot \mathrm{min}\right)$ & & $400.5(152.6) \wedge$ \\
\hline †HOMA-B beta-cell function index & & $1555.6(931.3)$ \\
\hline
\end{tabular}

${ }^{*}$ FSIGTT = Frequently Sampled Intravenous Glucose Tolerance Test.

† HOMA $=$ Homeostatic Model Assessment $\wedge$ In $\mathrm{N}=5$ subjects.

during twenty four hour assay period at $24 \mathrm{~h}$ post LPS, $p<0.001)$. These findings confirm the expected transient but robust cytokine and biomarker response to low-dose endotoxemia.

\section{Clinical and counter-regulatory responses to low-dose endotoxemia}

Following low dose endotoxin or placebo administration, there was no significant difference in subjective pain and clinical symptoms as assessed by the McGill questionnaire Visual Analogue Scale (VAS) (within subject ANOVA following LPS, $p=0.2$ ) and Present Pain Intensity (PPI) (within subject ANOVA following LPS, $p=0.12$ ). The slight trend in scores did not reach a statistically significant difference between LPS and placebo and is unlikely to be of clinical significance when placed in context of the typical flu-like symptomatic response to moderate dose LPS (3 ng/kg) (Additional file 1: Figure $\mathrm{S} 1)$. In addition, we observed no significant differences in body temperature (Figure 2A) or blood pressure (not shown) following low dose LPS compared to placebo while heart rate (Figure $2 \mathrm{~B}$ ) increased modestly at the 4-8 hour timeperiod following LPS $(p=0.04)$. There was a trend toward small increases in growth hormone (Figure 2C) (peak trend at 18 hours, $p=0.71$ ) and serum cortisol (Figure 2D) (peak change at six hours, $p<0.05$ ) following LPS. These data suggest a subclinical inflammatory response with very modest counter-regulatory hormone activation.

\section{Low-dose endotoxemia induces adipose tissue inflammation}

Low-dose endotoxemia induced modest inflammation in adipose tissue with increase in mRNA levels of several inflammatory genes known to modulate adipose and systemic insulin resistance (Figure 3). Thus, adipose tissue mRNA levels of IL-6 (peak 6-fold, ANOVA $F=27.5$, $p<0.001$ ) and TNF-alpha (peak 1.8-fold, $\mathrm{F}=2.9, p=0.01$ ) increased with MCP-1 (peak 10-fold, $\mathrm{F}=5.6, p<0.01$ ) and fractalkine (CX3CL1) (peak 15-fold, $\mathrm{F}=13.3$, $p<0.001)$, chemokines involved in monocyte and T-cell recruitment and implicated in adipose tissue inflammation and insulin resistance [22,23]. Previously, we have shown increases in levels of MCP1 [8] and fractalkine [10] proteins in adipose tissue following higher doses of LPS. Members of the suppressor of cytokine signaling (SOCS) family of proteins inhibit tyrosine kinase receptor signaling and are known to attenuate the insulin receptor and induce adipose insulin resistance [24,25]. Two of these, SOCS-1 (2.5-fold, $p=0.01)$ and SOCS-3 (3-fold, $p<0.01$ ) mRNAs increased modestly following low dose LPS. We did not observe significant changes in anti- inflammatory cytokine IL-10 or in SOCS 2 and SOCS 6 following LPS (data not shown).

\section{Low-dose endotoxemia induces systemic insulin resistance in humans}

We previously demonstrated that higher dose $(3 \mathrm{ng} / \mathrm{Kg})$ endotoxemia induced acute systemic IR without altering pancreatic beta-cell function [8]. However, at that dose the clinical and inflammatory changes were much greater than that observed in obesity and metabolic syndrome. Here, we observed a more modest decrease in insulin sensitivity at FSIGTT $(n=5)$ following low-dose endotoxemia; insulin sensitivity (SI) declined by $21 \%$ following LPS compared to placebo $(p<0.05)$ (Figure $4 \mathrm{~A}$ ) with no significant change in the AIRG index of pancreatic beta-cell function (placebo $463.02 \pm 161.4$ vs. LPS $\left.405.45 \pm 157.7\left(\mu \mathrm{U} \cdot \mathrm{ml}^{-1} \cdot \mathrm{min}\right), p=0.58\right)$. Consistent with the FSIGT data, insulin resistance estimated by HOMA- 


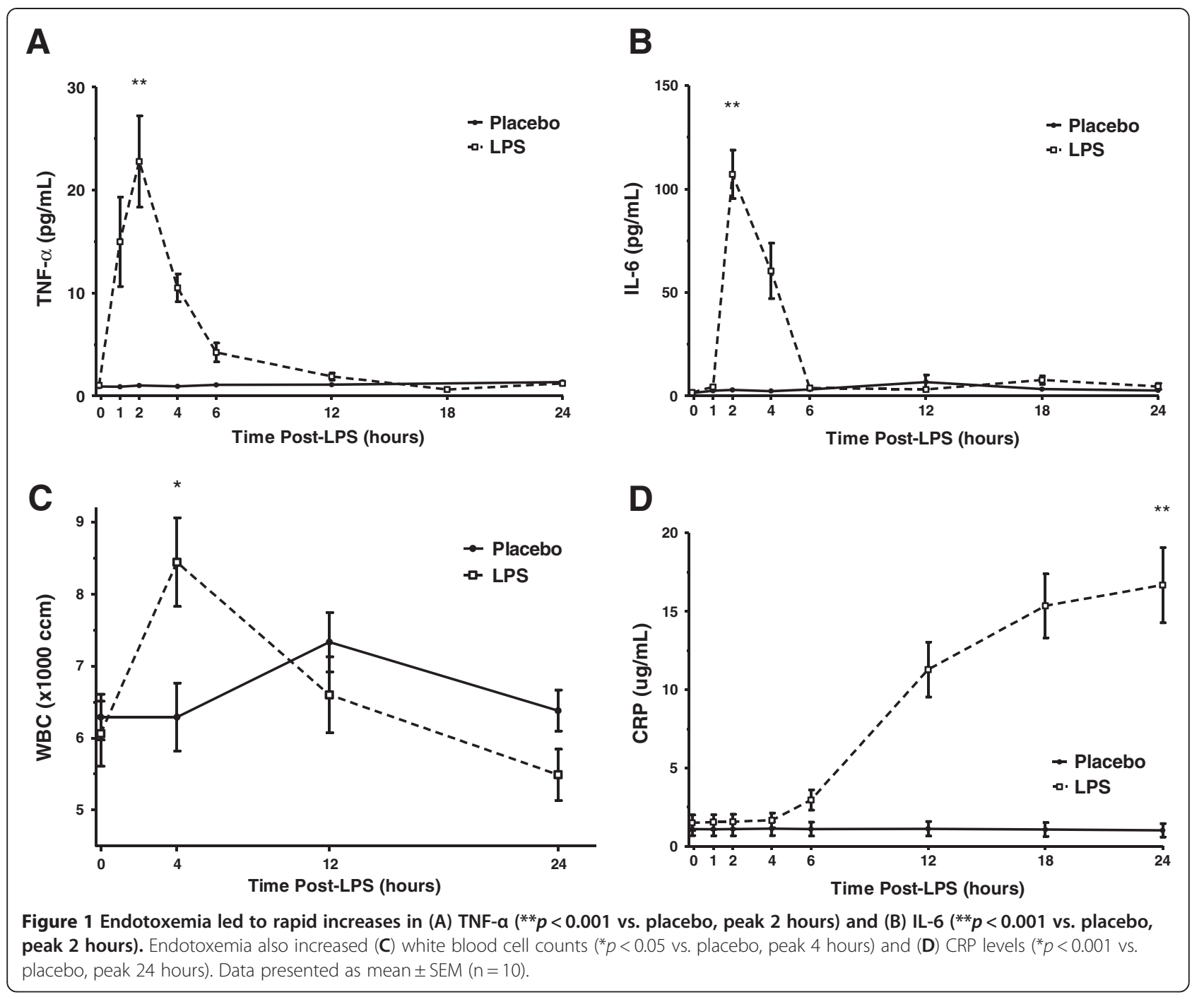

IR in the FSIGTT sub-sample $(\mathrm{n}=5)$ was $32 \%$ higher following LPS compared to placebo $(p<0.01)$ (Figure $4 \mathrm{~B}$ ) while HOMA-B data, a surrogate of fasting pancreatic beta-cell function, was unchanged (placebo $231.4 \pm 140.1$ vs. LPS $230.2 \pm 84.0, p=0.98)$. In the entire sample, HOMA IR showed the same pattern of increase (placebo $1.49 \pm 0.21$ vs. LPS $1.77 \pm 0.24, p=0.02$ ) as that observed in the FSIGTT sub-sample with no change in HOMA-B (placebo $235.4 \pm 131.4$ vs. LPS $232.2 \pm 96.1, p=0.9$ ). Overall, low dose endotoxemia produced systemic insulin resistance following induction of specific adipose inflammatory pathways (cytokines, chemokines and SOCS) that attenuate insulin signaling in vivo.

\section{Discussion}

In this double blind, placebo-controlled, random sequence crossover study of low-dose endotoxemia designed to minimize clinical symptoms, we observed several findings which support its potential use in the study of cardiometabolic diseases: 1) a robust biochemical systemic inflammatory response; 2) an almost complete lack of clinical responses; 3) minimal counter regulatory response in cortisol and growth hormone; 4) significant modulation of cytokine, chemokine in adipose tissue and insulin signaling pathways; and 5) induction of systemic insulin resistance without evidence of pancreatic beta cell dysfunction.

Experimental endotoxemia, which stimulates toll-like receptor 4 (TLR-4) signaling in vivo, may be an informative model to study cardio-metabolic traits in humans $[9,26]$. Observational data show that sepsis and chronic infection $[27,28]$ induce insulin resistance, glucose intolerance and lipid derangement resembling that observed in obesity, type-2 diabetes and atherosclerosis. In addition, we and others have shown that experimental endotoxemia induces insulin resistance $[8,9]$, adipose tissue inflammation [10] and atherogenic lipoprotein changes, including impaired reverse cholesterol transport 


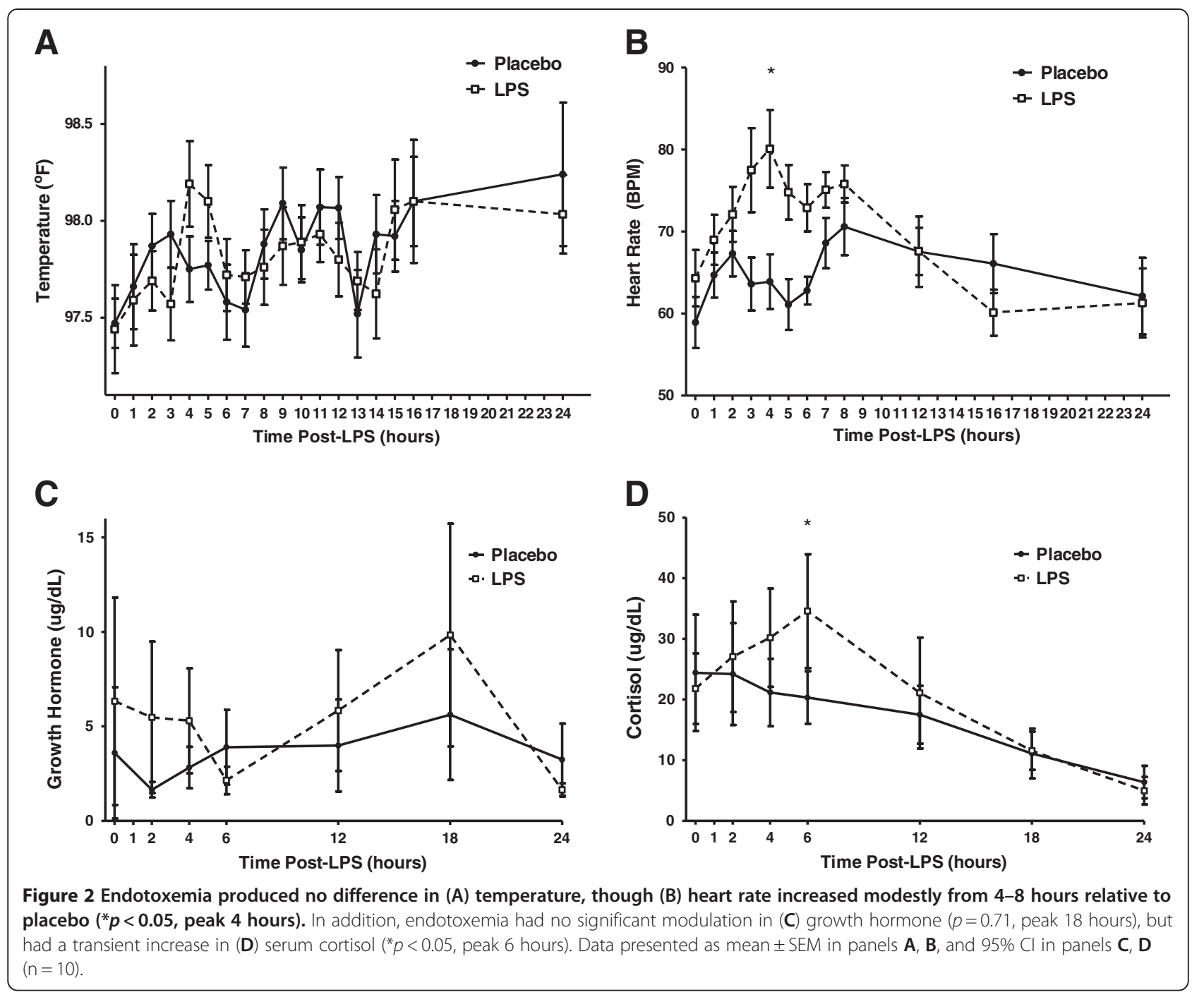

$[11,12,26,29,30]$. In humans, endogenous TLR4 antigens, including fatty acids [6] and oxidized lipids [31], are generated in obese adipose and atherosclerosis and may drive inflammatory cardio-metabolic dysfunction. Indeed, TLR4 is directly implicated in diet induced obesity [6] and atherosclerosis through studies in TLR4 deficient mouse models. Thus, endotoxemia has strong biological plausibility and activates relevant pathways known to be perturbed in obesity, diabetes and atherosclerosis.

We previously reported systemic inflammatory changes in adipose tissue with development of a systemic insulin resistance state [8] utilizing a moderate dose of endotoxin (3 $\mathrm{ng} / \mathrm{kg}$ ). Despite its utility in studying inflammatory effects on lipoproteins, metabolic function and adipose tissue in human, this proof-of-principle model is supraphysiologic and induces marked changes in systemic inflammatory markers compared to the current low-dose model and compared to that observed chronically in cardio-metabolic disease states. More importantly, moderate-dose endotoxemia is associated with overt clinical responses, including fever, tachycardia and flu-like aches $[8,10,15]$ which may limit wider application in large-scale human clinical research. In the current study, we demonstrate more subtle changes in inflammatory and metabolic responses with an absence of clinical symptoms during low-dose endotoxemia (LPS $0.6 \mathrm{ng} / \mathrm{kg}$ ). Our findings support the use of this low-dose model in studying clinically relevant metabolic changes while providing a safe and scalable approach for testing novel therapeutics and genomic influences on cardio-metabolic disorders.

In moderate dose endotoxemia [8], we observed strong induction of subcutaneous adipose TNF and IL-6 as well as MCP-1, which is known to recruit CCR-2 expressing monocytes, increase inflammatory-M1 adipose tissue macrophage (ATM) and promote insulin resistance [22]. In support of this concept, we also observed increased 

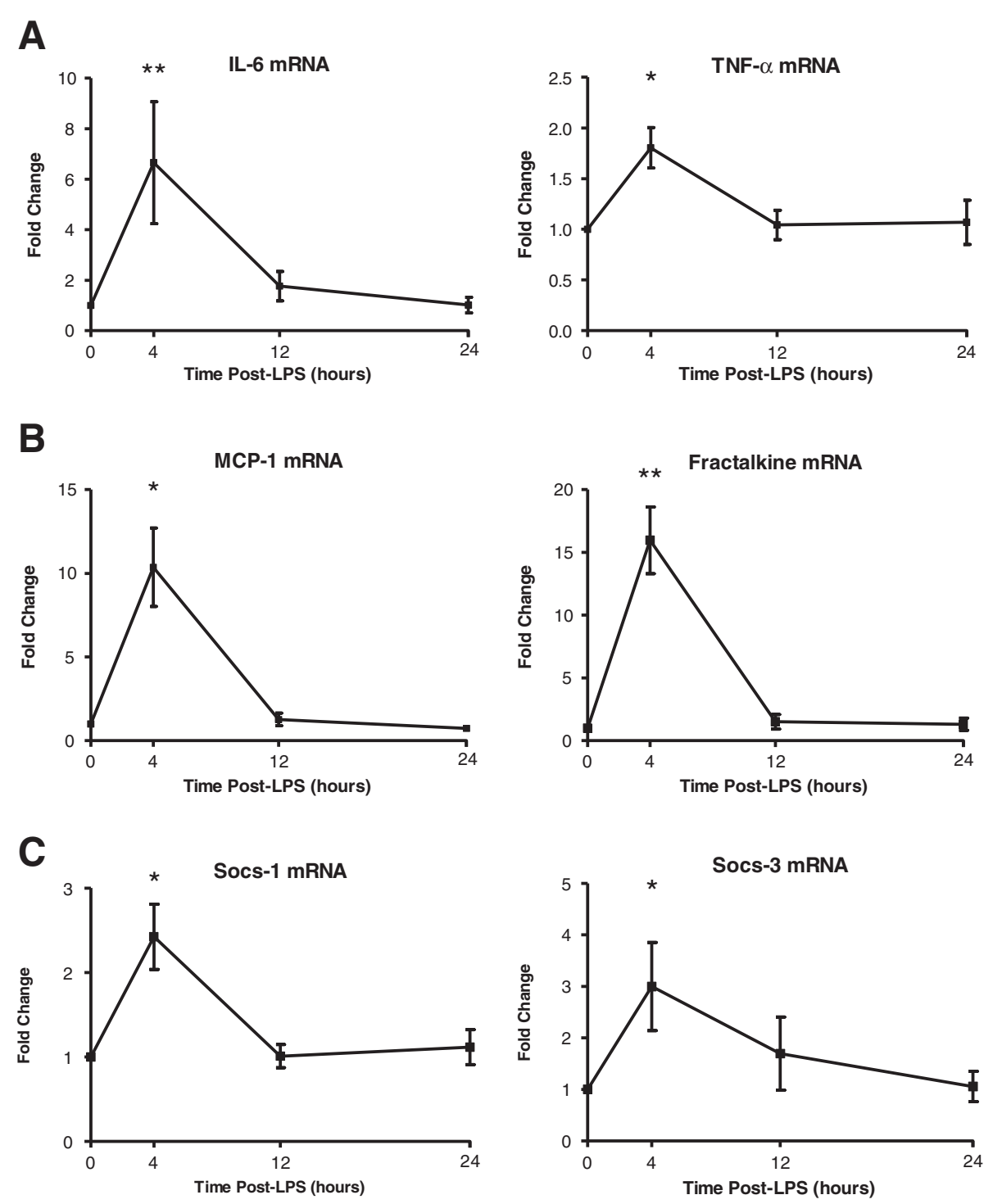

Figure 3 Endotoxemia increased adipose mRNA levels of cytokines (A) IL- 6 and TNF-a, chemokines (B) MCP-1 and fractalkine and (C) SOCS-1 and SOCS-3. $\left.{ }^{*} p<0.05,{ }^{* *} p<0.001\right)$. Data presented as mean \pm SEM $(n=10)$.

mRNA levels of the macrophage marker, EMR1-F4/80 [32], in adipose tissue. Thus, endotoxemia may promote adipose recruitment of macrophages, a characteristic of adipose tissue in obese, insulin resistant humans ${ }^{33}$. In our current study, we demonstrate that low dose endotoxemia produced a more subtle adipose tissue inflammation. However, the increases in adipose cytokines and chemokines as well as induction of SOCS were similar to those observed in diet and obesity-related insulin resistance [22,32-37]. Further, adipose changes coincided with subsequent emergence of modest insulin resistance which was less than that with higher dose endotoxin but consistent with that in metabolic syndrome [38] and diabetes [19]. Thus, low dose endotoxemia also provides a model of inducible adipose tissue inflammation permitting specific interrogation of factors that modulate this important tissue component of insulin resistance.

Epidemiological studies have demonstrated a consistent relationship between chronic low grade inflammation and states of obesity, insulin resistance, diabetes and atherosclerosis. A challenge in understanding the mechanism of these associations in humans however remains hampered by a lack of a reliable in vivo model. Here we show that an evoked inflammatory model to simulate these states can be fruitful in identifying genes and pathways activated in cardio-metabolic disease. We acknowledge that the low dose endotoxemia model does not reproduce the chronic pathophysiology of complex cardio-metabolic diseases. It is, however, associated with minimal clinical response and approximates acutely the 

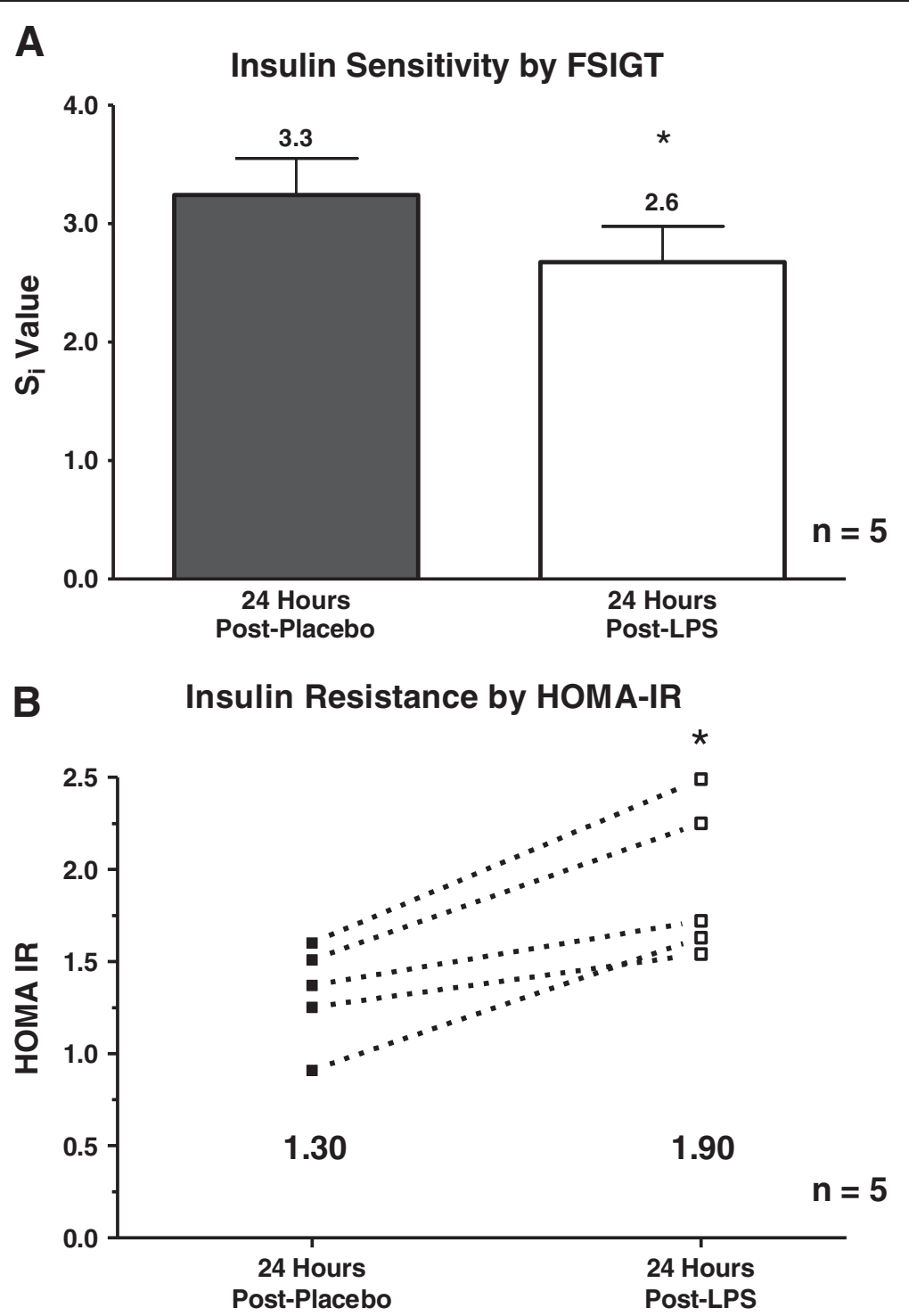

Figure 4 Endotoxemia led to a systemic insulin resistant state as shown by $(A)$ a decrease in the insulin sensitivity index $\left(\mathrm{S}_{\mathrm{i}}\right)$ at FSIGT testing (placebo $3.31 \pm 0.62$ vs LPS $2.60 \pm 0.63\left(\mu \mathrm{U} / \mathrm{ml}^{-1}{ }^{-1} \cdot \mathrm{min}^{-1},{ }^{*} p<0.05, \mathrm{n}=5\right.$. Consistent with this decrease in insulin sensitivity, endotoxemia increased (B) HOMA-IR compared to placebo $\left({ }^{*} p<0.05, \mathrm{n}=5\right)$.

inflammatory and metabolic responses of the chronic disease states of interest. Furthermore, low-dose experimental endotoxin induction of toll-like receptor 4 (TLR-4) signaling in vivo is one well established model of inflammation-induced metabolic disturbances in humans. Sepsis and chronic infections in humans induce insulin resistance, glucose intolerance and lipoprotein changes similar to the metabolic profile observed in obesity, type- 2 diabetes and established coronary artery disease. The insulin resistance, adipose inflammation and lipoprotein changes observed acutely during experimental endotoxemia resemble those observed chronically in cardiometabolic disease states. Finally, the role of TLR4 (the endotoxin signaling receptor) is further suggested by studies demonstrating reduced diet induced obesity and atherosclerosis in TLR4 deficient mouse models. Indeed, in addition to endotoxin, TLR4 may be activated by endogenous ligands that are increased in diet induced obesity and insulin resistance. Of further relevance to obesity and metabolic disease in vivo, rodents raised in germ-free conditions are protected from diet induced obesity [39]. Therefore, our model of induced inflammation from acute bacterial exposure is one of several models of inflammation evoked metabolic disturbance in vivo and may not exactly mimic all means of generating subclinical inflammation in obesity, diabetes and cardiovascular disease. However, this model also offers the additional 
advantage in permitting direct assessment of the directional impact of induced inflammation on metabolic parameters such as insulin resistance. This avoids confounding and reverse causation that are features of observational studies where inflammatory changes may result from risk factors and disease rather than be causal.

\section{Conclusion}

In summary, we present a low dose human endotoxemia model of inflammation which induces adipose tissue inflammation and systemic insulin resistance in the absence of overt clinical response. Such a model has the potential for broad and safe application in the study of novel therapeutics and genomic influences in cardio-metabolic disease.

\section{Abbreviations}

IR: Insulin Resistance; TLR-4: Toll-like receptor 4; LPS: lipopolysaccharide; CTRC: Clinical Translational Research Center; IV: Intravenous; FSIGTT: Frequently sampled intravenous glucose tolerance test; EDTA: Ethylenediaminetrichloroacetic acid; RIA: Radio-immunoassays; TNF: Tumor Necrosis factor a; IL: Interleukin; ELISA: Enzyme linked immuosorbent assay; RT-PCR: Real time Polymerase chain reaction; QPCR: Quantitative PCR; SOCS: Suppressor of cytokine signaling; MCP1: Monocyte chemoattractant protein-1; Sl: Sensitivity Index; AIRg: Acute insulin response to glucose; HOMA-IR: Homeostatic model assessment of insulin resistance; HOMA-B: Homeostatic model assessment of beta cells of pancreas; ANOVA: Analysis of Variance; BMI: Body Mass Index; HDL-C: High Density Lipoprotein Cholesterol; TG: Triglycerides.

\section{Competing interests}

The authors declare that they have no competing interests.

\section{Authors' contribution}

NNM and MPR designed and executed the study and wrote the manuscript $\mathrm{SPH}, \mathrm{JEF}, \mathrm{RDS}, \mathrm{CH}, \mathrm{KT}$, RS collected data and revised the manuscript. PNP, PK and MRR analyzed data and revised the manuscript and JTM collected the data. All authors have read and approved the final manuscript.

\section{Acknowledgements}

We are indebted to the Clinical Translational Research Center staff at UPenn, and in particular the nursing staff whose efforts help make this work possible. This work was supported by award from the National Institutes of Health $(\mathrm{NIH})$ including a Clinical and Translational Science Award (UL1RR024134) from the National Center for Research Resources and a Diabetes and Endocrine Research Center award (P20DK 019525), both to UPenn, and by R01 HL-073278 and a P50 HL083799-SCCOR Project award (to M.P.R). N.N.M. is supported by 5K23HL097151 from NIH. M.P.R. is also supported by R01-DK-090505, R01-DK071224, U01-HL108636 and K24-HL107643 from the NIH. R.S. is supported by the UPenn Clinical and Translational Science Award K12 KL1RR024132 from NIH.

\section{Author details}

${ }^{1}$ Cardiovascular Institute, Perelman School of Medicine at the University of Pennsylvania, Philadelphia, PA, USA. ${ }^{2}$ Institute for Diabetes, Endocrine and Metabolism, Perelman School of Medicine at the University of Pennsylvania, Philadelphia, PA, USA. ${ }^{3}$ Department of Pathology and Laboratory Medicine, Perelman School of Medicine at the University of Pennsylvania, Philadelphia, PA, USA. ${ }^{4}$ Cardiovascular Institute, Perelman School of Medicine at the University of Pennsylvania, 6 Penn Tower, 3400 Civic Center Blvd, Philadelphia, PA, USA.

Received: 19 March 2012 Accepted: 31 May 2012

Published: 18 June 2012

\section{References}

1. Shoelson SE, Lee J, Goldfine AB: Inflammation and insulin resistance. J Clin Invest 2006, 116:1793-1801

2. Pradhan AD, Manson JE, Rifai N, Buring JE, Ridker PM: C-reactive protein interleukin 6, and risk of developing type 2 diabetes mellitus. Jama 2001, 286:327-334

3. Haffner SM: Insulin resistance, inflammation, and the prediabetic state. Am J Cardiol 2003, 92:18J-26J.

4. Jeppesen J, Hansen TW, Rasmussen S, Ibsen H, Torp-Pedersen C, Madsbad S: Insulin resistance, the metabolic syndrome, and risk of incident cardiovascular disease: A population-based study. J Am Coll Cardiol 2007, 49:2112-2119.

5. Van Cromphaut SJ, Vanhorebeek I, Van den Berghe G: Glucose metabolism andinsulin resistance in sepsis. Curr Pharm Des 2008, 14:1887-1899.

6. Shi H, Kokoeva MV, Inouye K, Tzameli I, Yin H, Flier JS: Tlr4 links innate immunity and fatty acid-induced insulin resistance. J Clin Invest 2006, 116:3015-3025

7. Michelsen KS, Wong MH, Shah PK, Zhang W, Yano J, Doherty TM, Akira S, Rajavashisth TB, Arditi M: Lack of toll-like receptor 4 or myeloid differentiation factor 88 reduces atherosclerosis and alters plaque phenotype in mice deficient in apolipoprotein e. Proc Natl Acad Sci U S A 2004, 101:10679-10684.

8. Mehta NN, McGillicuddy FC, Anderson PD, Hinkle CC, Shah R, Pruscino L Tabita-Martinez J, Sellers KF, Rickels MR, Reilly MP: Experimental endotoxemia induces adipose inflammation and insulin resistance in humans. Diabetes 2010, 59:172-181

9. Agwunobi AO, Reid C, Maycock P, Little RA, Carlson GL: Insulin resistance and substrate utilization in human endotoxemia. J Clin Endocrinol Metab 2000, 85:3770-3778.

10. Shah R, Lu Y, Hinkle CC, McGillicuddy FC, Kim R, Hannenhalli S, Cappola TP, Heffron S, Wang X, Mehta NN, Putt M, Reilly MP: Gene profiling of human adipose tissue during evoked inflammation in vivo. Diabetes 2009, 58:2211-2219.

11. Suffredini AF, Fantuzzi G, Badolato R, Oppenheim JJ, O'Grady NP: New insights into the biology of the acute phase response. $J$ Clin Immunol 1999, 19:203-214.

12. McGillicuddy FC, de la Llera Moya M, Hinkle CC, Joshi MR, Chiquoine EH, Billheimer JT, Rothblat GH, Reilly MP: Inflammation impairs reverse cholesterol transport in vivo. Circulation 2009, 119:1135-1145.

13. Melzack $R$ : The mcgill pain questionnaire: Major properties and scoring methods. Pain 1975, 1:277-299.

14. Bergman RN, Prager R, Volund A, Olefsky JM: Equivalence of the insulin sensitivity index in man derived by the minimal model method and the euglycemic glucose clamp. J Clin Invest 1987, 79:790-800.

15. Anderson PD, Mehta NN, Wolfe ML, Hinkle CC, Pruscino L, Comiskey LL, TabitaMartinez J, Sellers KF, Rickels MR, Ahima RS, Reilly MP: Innate immunity modulates adipokines in humans. J Clin Endocrinol Metab 2007, 92:101-112.

16. Reilly MP, Iqbal N, Schutta M, Wolfe ML, Scally M, Localio AR, Rader DJ, Kimmel SE: Plasma leptin levels are associated with coronary atherosclerosis in type 2 diabetes. J Clin Endocrinol Metab 2004, 89:3872-3878

17. Reilly MP, Wolfe ML, Localio AR, Rader DJ: C-reactive protein and coronary artery calcification: The study of inherited risk of coronary atherosclerosis (sirca). Arterioscler Thromb Vasc Biol 2003, 23:1851-1856.

18. Livak KJ, Schmittgen TD: Analysis of relative gene expression data using real-time quantitative pcr and the $2(-$ delta delta $\mathrm{c}(\mathrm{t}))$ method. Methods 2001, 25:402-408.

19. Rickels MR, Naji A, Teff KL: Insulin sensitivity, glucose effectiveness, and free fatty acid dynamics after human islet transplantation for type 1 diabetes. J Clin Endocrinol Metab 2006, 91:2138-2144.

20. Finegood DT, Hramiak IM, Dupre J: A modified protocol for estimation of insulin sensitivity with the minimal model of glucose kinetics in patients with insulin dependent diabetes. J Clin Endocrinol Metab 1990, 70:1538-1549.

21. Boston RC, Stefanovski D, Moate PJ, Sumner AE, Watanabe RM, Bergman $\mathrm{RN}$ : Minmod millennium: A computer program to calculate glucose effectiveness and insulin sensitivity from the frequently sampled intravenous glucose tolerance test. Diabetes Technol Ther 2003, 5:1003-1015.

22. Weisberg SP, Hunter D, Huber R, Lemieux J, Slaymaker S, Vaddi K, Charo I, Leibel RL, Ferrante AW Jr: Ccr2 modulates inflammatory and metabolic effects of high-fat feeding. J Clin Invest 2006, 116:115-124. 
23. Shah R, Hinkle CC, Ferguson JF, Mehta NN, Li M, Qu L, Lu Y, Putt ME, Ahima RS, Reilly MP: Fractalkine is a novel human adipochemokine associated with type 2 diabetes. Diabetes 2011, 60:1512-1518.

24. Ueki K, Kondo T, Kahn CR: Suppressor of cytokine signaling 1 (socs-1) and socs-3 cause insulin resistance through inhibition of tyrosine phosphorylation of insulin receptor substrate proteins by discrete mechanisms. Mol Cell Biol 2004, 24:5434-5446.

25. Kawazoe Y, Naka T, Fujimoto M, Kohzaki H, Morita Y, Narazaki M, Okumura K, Saitoh H, Nakagawa R, Uchiyama Y, Akira S, Kishimoto T: Signal transducer and activator of transcription (stat)-induced stat inhibitor 1 (ssi-1)/ suppressor of cytokine signaling 1 (socs1) inhibits insulin signal transduction pathway through modulating insulin receptor substrate 1 (irs1) phosphorylation. J Exp Med 2001, 193:263-269.

26. Hudgins LC, Parker TS, Levine DM, Gordon BR, Saal SD, Jiang XC, Seidman CE, Tremaroli JD, Lai J, Rubin AL: A single intravenous dose of endotoxin rapidly alters serum lipoproteins and lipid transfer proteins in normal volunteers. $J$ Lipid Res 2003, 44:1489-1498.

27. Copeland S, Warren HS, Lowry SF, Calvano SE, Remick D: Acute inflammatory response to endotoxin in mice and humans. Clin Diagn Lab Immunol 2005, 12:60-67.

28. Grunfeld C, Pang M, Doerrler W, Shigenaga JK, Jensen P, Feingold KR: Lipids, lipoproteins, triglyceride clearance, and cytokines in human immunodeficiency virus infection and the acquired immunodeficiency syndrome. J Clin Endocrinol Metab 1992, 74:1045-1052.

29. Paradis ME, Badellino KO, Rader DJ, Deshaies Y, Couture P, Archer WR, Bergeron N, Lamarche B: Endothelial lipase is associated with inflammation in humans. J Lipid Res 2006, 47:2808-2813.

30. Memon RA, Grunfeld C, Moser AH, Feingold KR: Tumor necrosis factor mediates the effects of endotoxin on cholesterol and triglyceride metabolism in mice. Endocrinology 1993, 132:2246-2253.

31. Yang K, He YS, Wang XQ, Lu L, Chen QJ, Liu J, Sun Z, Shen WF: Mir-146a inhibits oxidized low-density lipoprotein-induced lipid accumulation and inflammatory response via targeting toll-like receptor 4 . FEBS Lett 2011, 585:854-860.

32. Khazen W, M'Bika JP, Tomkiewicz C, Benelli C, Chany C, Achour A, Forest C: Expression of macrophage-selective markers in human and rodent adipocytes. FEBS Lett 2005, 579:5631-5634.

33. Weisberg SP, McCann D, Desai M, Rosenbaum M, Leibel RL, Ferrante AW $\mathrm{Jr}$ : Obesity is associated with macrophage accumulation in adipose tissue. J Clin Invest 2003, 112:1796-1808.

34. Kim F, Pham M, Luttrell I, Bannerman DD, Tupper J, Thaler J, Hawn TR, Raines EW, Schwartz MW: Toll-like receptor-4 mediates vascular inflammation and insulin resistance in diet-induced obesity. Circ Res 2007, 100:1589-1596.

35. Tsukumo DM, Carvalho-Filho MA, Carvalheira JB, Prada PO, Hirabara SM, Schenka AA, Araujo EP, Vassallo J, Curi R, Velloso LA, Saad MJ: Loss-offunction mutation in toll-like receptor 4 prevents diet-induced obesity and insulin resistance. Diabetes 2007, 56:1986-1998.

36. Uysal KT, Wiesbrock SM, Marino MW, Hotamisligil GS: Protection from obesity-induced insulin resistance in mice lacking tnf-alpha function. Nature 1997, 389:610-614.

37. Kanda H, Tateya S, Tamori Y, Kotani K, Hiasa K, Kitazawa R, Kitazawa S, Miyachi H, Maeda S, Egashira K, Kasuga M: Mcp-1 contributes to macrophage infiltration into adipose tissue, insulin resistance, and hepatic steatosis in obesity. J Clin Invest 2006, 116:1494-1505.

38. Haffner SM, Miettinen $\mathrm{H}$, Stern MP: The homeostasis model in the san antonio heart study. Diabetes Care 1997, 20:1087-1092.

39. Rabot S, Membrez M, Bruneau A, Gerard P, Harach T, Moser M, Raymond F, Mansourian R, Chou CJ: Germ-free c57bl/6j mice are resistant to high-fat-diet-induced insulin resistance and have altered cholesterol metabolism. FASEB J 2010, 24:4948-4959.

doi:10.1186/1479-5876-10-124

Cite this article as: Mehta et al:: A human model of inflammatory cardio-metabolic dysfunction; a double blind placebo-controlled crossover trial. Journal of Translational Medicine 2012 10:124.

\section{Submit your next manuscript to BioMed Central and take full advantage of:}

- Convenient online submission

- Thorough peer review

- No space constraints or color figure charges

- Immediate publication on acceptance

- Inclusion in PubMed, CAS, Scopus and Google Scholar

- Research which is freely available for redistribution

Submit your manuscript at www.biomedcentral.com/submit
( BioMed Central 